on the rate of the hydrolysis than has the inductive effect and, on the basis of the reaction mechanism, this can also be expected. As compared with the ethylenic esters the decrease in the rate is due to the inductive effect of the triple bond. As a result of this either the pre-equilibrium moves from the side of the ionic conjugate acid of ester to the side of the ester or the alkoxyl linkage, after the addition of water, is less readily breakable.

The rates of hydrolysis in $60 \%$ aqueous ethanol at $60^{\circ} \mathrm{C}$ for the ethyl ester of acetic, monochloroacetic, dichloroacetic and trichloroecetic acids are $1,0.91,0.40$ and 0.11 , respectively, if the rate for ethyl acetate is taken as a unity ${ }^{5}$. The fact that the rates of hydrolysis for the ethyl ester of propiolic and acrylic acids differ only slightly from each other gives support to the assumption that, in the case of chloroacetic acids, steric factors are of importence.

1. Halonen, E. A. Acta Chem. Scand. 9 (1955) 1492.

2. Halonen, E. A. Ann. Acad. Sci. Fennicae A. II. 55 (1954).

3. Tommila, E. and Hella, A. Ann. Acad. Sci. Fennicae A. II. 53 (1954).

4. Pekkarinen, L. Ann. Acad. Sci. Fennicae A. II. 55 (1955).

5. Timm, E. W. and Hinshelwood, C. N. J. Chem. Soc. 1938 862; Tommila, E., Hietala, S. and Nyrkiö, J. Suomen Kemistilehti B. 28 (1955) 143; Ingold, C. K. Structure and Mechanism in Organic Chemistry, Cornell University Press, New York 1953, p. 777.

Received September 20, 1956.

\section{Paper Chromatographic Separation of Thiamine Phosphates}

KARL-HEINZ KIESSLING

Institute of Zoophysiology, Uppsala, Sweden

Geveral papers have been published Nabout paper chromatographic separa. tion of thiamine phosphates ${ }^{1-5}$. In all solvents described thiamine triphosphate hardly moves at all, and its $R_{F}$ value coincides in most cases with that of nucleotide di- and triphosphates.

In this paper a paper chromatographic solvent is described in which thiamine tri- phosphate moves easily, and in which it separates well from other thiamine com. pounds and from nucleotide phosphates. Also thiamine phosphates with more than three phosphate groups are separated. From a mixture of thiamine phosphates prepared according to Viscontini, Bonetti, and Karrer ", nine thiamine compounds can be isolated.

The solvent consists of $100 \mathrm{ml}$ isobutyric acid, $60 \mathrm{ml} \mathrm{N}$ ammonia, and $1.6 \mathrm{ml} 0.1 \mathrm{M}$ ethylene diamine tetrascetic acid. It has been used by Krebs and Hems for separat. ing nucleotides ${ }^{7}$ and is a modification of a solvent described by Zetterström and Ljunggren ${ }^{8}$. Filter papers Whatman No. 1 are used after washing in aqueous ethylene diamine tetraacetic acid according to the method described by Eggleston and Hems?

The di- and triphosphates of inosine, guanosine, uridine, and cytidine all have lower $R_{F}$ values than adenosine diphosphate ${ }^{10}$. In this investigation thiamine triphosphate was shown to move faster then adenosine diphosphate. It can thus be easily separated from the nucleotides mentioned.

Fig. 1 and 2 show the separation of different amounts of thiamine phosphates prepared according to Viscontini et al." One $\mathrm{mg}$ of the mixture dissolved in water is linearly spread on the filter paper in Fig. 1. The separation is very distinct. Ten lines can be seen with the naked eye, but only nine are registered on the photographic plate. When the amount of the thiamine phosphate mixture is increased to $3 \mathrm{mg}$ (Fig. 2) the separation is still distinct except between thiamine monoand diphosphate (lines 3 and 4). Nine lines can be detected.

The lines are cut out, the compounds run off with water, then added as spots on a new filter paper, and developed in the same solvent. The compounds appear as distinct spots with about the same $R_{F}$ values as the lines on the original paper chromatogram (Fig. 3).

Total and hydrolyzable phosphorus per molecule of thiamine for the compounds $1-7$ are seen in Table 1. Thus compound 1 and 2 were identified as different forms of thiamine*. The ratio between totel and hydrolyzable phosphorus and thiamine suggests that the compounds 3-7 are thiamine mono-, di-, tri-, tetra- and pentaphosphate, respectively. Compounds

* These two forms have been separated earlier by Gaudiano, Spadoni and Tecce ${ }^{11}$.

Acta Chem. Scand. 10 (1956) No. 8 


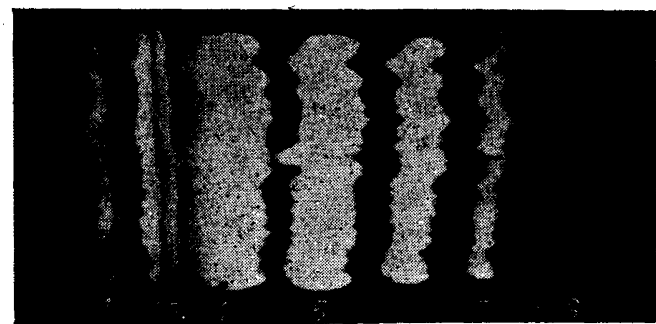

Fig. 1. Paper chromatographic separation of a mixture of thiamine phosphates.

$1 \mathrm{mg}$ of the mixture prepared according toViscontini et al. and dissolved in water is spread as a line on the filter paper. For solvent see text. Time $19 \mathrm{~h}$. The thiamine compounds on the chromatogram are made visible by spraying the paper with an alkaline ferricyanide solution. In UV of $340 \mathrm{~m} \mu$ they are seen as blue lines.

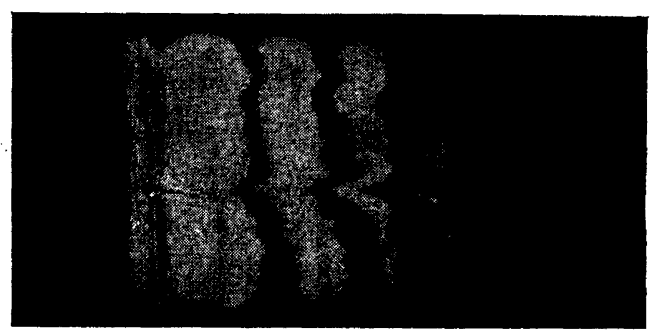

Fig. 2. Paper chromatographic separation of a mixture of thiamine phosphates.

$3 \mathrm{mg}$ of the mixture is dissolved in water, and placed on the filter paper. Other conditions as in Fig. 1.

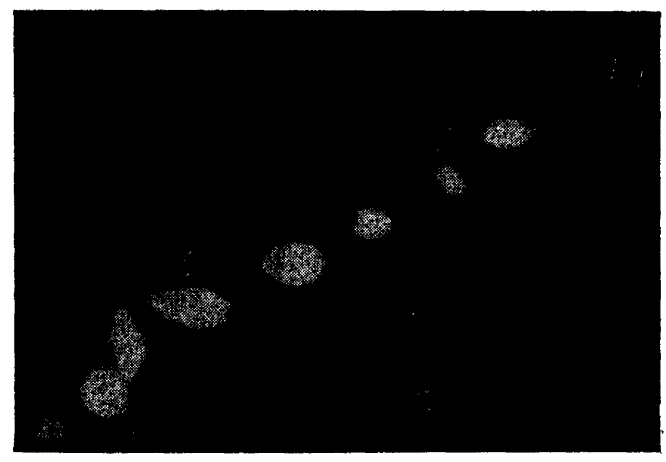

Fig. 3. Subsequent test chromatography of the compounds separated in Fig. 1.

The lines from the ehromatogram in Fig. 1 are added as separate spots on a new filter paper, and run with the same solvent. The figures correspond to those in Fig. 1 and in Table 1.

Acta Chem. Scand. 10 (1956) No. 8 
Table 1. Total and hydrolyzable phosphorus of the thiamine compounds sepanated as in Fig. 1.

Hydrolyzable phosphorus is determined after heating the compounds in $2 \mathrm{~N} \mathrm{HCl}$ at $100^{\circ}$ for 10 min., after which all thismine polyphosphates appear as thiamine monophosphate. Total phosphorus is determined after wet ashing. Thiamine is oxidized with alkaline ferricyanide to thioohrome, and the fluorescence estimated in a Bookman spectrophotometer with fluores. cence attachment.

\begin{tabular}{|c|c|c|c|}
\hline Compound & $\begin{array}{l}\text { hydrolyz- } \\
\text { oble P } \\
\text { total P }\end{array}$ & $\frac{\mathbf{P}}{\operatorname{thiamin} \theta}$ & $R_{F}$ value \\
\hline $\begin{array}{c}1 \\
2 \\
3 \\
4 \\
5 \\
6 \\
7 \\
8-10\end{array}$ & $\begin{array}{l}- \\
- \\
\overline{1 / 2} \\
2 / 3 \\
3 / 4 \\
4 / 5\end{array}$ & $\begin{array}{r}- \\
1 \\
2 \\
3 \\
4 \\
5 \\
>5\end{array}$ & \begin{tabular}{|c}
0.87 \\
0.79 \\
0.77 \\
0.68 \\
0.55 \\
0.46 \\
0.36 \\
$0.24,0.21$ \\
0.16
\end{tabular} \\
\hline
\end{tabular}

8-10 have more than five phosphate groups per molecule of thiamine.

The described method has been used for isolating biological thiamine triphosphate from yoast 12, and was found satisfactory. for this purpose. The $R_{F}$ value, however, is somewhat lower than for the synthetic compound depending on the contamination with impurities from the yeast.

1. Viscontini, M., Bonetti, G., Ebnother, C. and Karrer, P. Helv. Chim. Acta 34 (1951) 1384.

2. Rossi-Fanelli, A., Siliprandi, N. and Fasella, P. Science 116 (1952) 711.

3. Kiessling, K.-H. and Lindahl, G. Arleiv Kemi 6 (1953) 271.

4. Bartley, W. Biochem. J. London 56 (1954) 379.

5. Siliprandi, D. and Siliprandi, N. Biochim. et Biophys. Acta 14 (1954) 52.

6. Viscontini, M., Bonetti, G. and Karrer, P. Helv. Chim. Acta 33 (1949) 1478.

7. Krebs, H. A. and Hems, R. Biochim. et Biophys. Acta 12 (1953) 172.

8. Zetterström, R. and Ljunggren, M. Acta Chem. Scand. 5 (1951) 291.

9. Eggleston, L. V. and Hems, R. Biochem. J. London 52 (1952) 156.

10. Hems, R. Personal communication.
11. Gaudiano, A., Spadoni, M. A. and Tecoe, G. Boll. Soc. it. Biol. Sper. 28 (1952) 701.

12. Kiesaling, K.-H. Biochim. et Biophys. Acta 20 (1956) 293.

Received August 8, 1956.

isoThiocyanates XXIII*. I (-). 9-Methylsulphinylnonyl isoThiocyanate, a New Mustard Oil Present as a Glucoside (Glucoarabin) in Arabis Species

ANDERS BJER and ROLF GMELIN

Chemical Laboratory of the University of Copenkagen, Denmark

Tn the course of a systematic investigaItion of glucosidically bound isothiocya. nates in seeds of various species of the cruciferous genus Arabis, it was observed that a glucoside, obviously different from all compounds heretofore recognized in Nature, was present in, e.g., Arabis alpina L., a popular flower-garden subject. Paper chromatograms of seed extracts 1 indicated the presence of two glucosides both possessing $\boldsymbol{R}_{F}$-values well above that of glucotro. paeolin (cf. Ref. ${ }^{2}$ ).

When a purified, methanolic extract of a larger seed sample was subjected to enzymic hydrolysis in a buffered solution (pH 6.5), an ether-soluble isothiocyanate fraction was formed. Homogeneous, optically active, crystalline thioureas were obtained upon reaction of the isothiocyanate solution with various amines. The analytical data clearly indicated the composition $\mathrm{C}_{12} \mathrm{H}_{21} \mathrm{ONS}_{2}$ for the parent mustard oil. The thiourea, recrystallized from ethyl acetate, had the m. p. 103.5 - 104.5 (uncorr.) (Found: C 50.00; H 9.13; N 10.45; S 24.40. Calc. for $\mathrm{C}_{12} \mathrm{H}_{24} \mathrm{ON}_{2} \mathrm{~S}_{2}$ : C 49.96; H 9.15; $\mathrm{N}, 10.60 ; \mathrm{S} 24.25),[a]_{\mathrm{D}}^{24.6}-66^{\circ}(96 \%$ EtOH, $c=2.1$ ). The infra-red spectrum in a $\mathbf{K B r}$-wafer showed a characteristic strong band at $9.78 \mu$, attributable to a sulphoxide-grouping. The phenylthiourea separated from ethyl acetate in colourless prisms, m. p. $121-122^{\circ}$ (uncorr.) (Found:

* Part XXII of this series: Acta Chem. scand. 10 (1956) 1193.

Acta Chem. Scand. 10 (1956) No. 8. 